\title{
Improving the effective communication soft skill in higher education engineering studies: an experience through written reports
}

\author{
Marcos Carreres ${ }^{\mathrm{a}}$, Luis Miguel Garcia-Cuevas ${ }^{\mathrm{b}}$, Pedro Marti-Aldaravi ${ }^{\mathrm{c}}$, Roberto \\ Navarro ${ }^{\mathrm{d}}$ \\ Universitat Politècnica de València, Spain, ${ }^{a}$ marcarta@mot.upv.es, bluiga12@mot.upv.es, \\ cpedmar15@mot.upv.es, ${ }^{\mathrm{d}}$ ronagar1@ mot.upv.es
}

\begin{abstract}
With the new paradigm of higher education, courses syllabus are not only addressed to develop the knowledge in some specific contents, but also to let the student acquire a set of the so-called transversal competences or soft skills. Amongst these, the ability of the students to communicate in an effective manner is a soft skill that will present a key role in the future careers of the students. In this paper, the experience in two courses of the Aerospace Engineering Bachelor Degree working on the effective communication through written technical reports is presented. Different enhancements have been introduced over the years, including specific sessions to present best practices for written reports, assessment using rubrics or intermediate deliveries to provide feedback to the students before they deliver the final report. The analyzed courses belong to consecutive years and are taught in both Spanish and English, which provides a wide view for understanding the impact of each feature. With the current configuration, significant improvement in the students written reports readability is obtained. Their works are more rigorous in terms of writing and format. Nevertheless, the effect of these new features on the technical content of the reports is slight. Overall, the content is transmitted by the students in a more effective manner.
\end{abstract}

Keywords: key skills, scoring rubrics, transversal competences, effective communication, evaluation. 


\section{Introduction}

For more than 20 years now, companies have been transmitting to universities their concern about the skills acquired by students in their training cycle. Among others, such as a good understanding of engineering science fundamentals (mathematics, physics, computing...), one of the desired attributes of an engineer is good communication skills (written, oral, graphic and listening) (The Boeing Company 1996).

Part of the responsibility of developing such skills relies on the university, in cooperation with their "customers" (i.e. industry, academy, administrations...), and in recognition of their own local resources and constraints. The implementation of the Bologna system (The Bologna Declaration 1999) was the result of the requirements of these "customers", promoting the students to demonstrate (Crooks 1988) not only knowledge of the basis but also a series of competences at the end of their formation.

Under this scope, the Universitat Politècnica de València (UPV) was one of the precursors in the design of a work plan based on a series of 13 specific competences or soft skills, assigned to each course or subject (UPV 2015). These soft skills are characterized for being integrating, transferable, independent, multi-functional and evaluable. Three levels of control are established within them: first level (developed during the 1st and 2nd years of Bachelor's degrees), second level (3rd and 4th years), and third level (acquired in a Master's degree).

The soft skill number '08 - Effective communication' is investigated in this work. This constitutes a key interpersonal skill for many jobs. Effective communication is more than just exchanging information, it is about understanding the intentions behind the information transmitted in the fastest and most direct way. Among the different communication channels, written communication is the one analyzed in this case. Although there are many guides for achieving effective written communication (Koehler 2001), this skill needs to be trained and consequently evaluated (Yusof 2015, Masoud 2019).

This document describes the actions carried out in the frame of two courses of the Aerospace Engineering Degree at UPV that act as "control points" for the aforementioned soft skill. This implies the students face activities planned to develop this skill, followed by an evaluation of their achievements. Indicators for comparison are reported from the academic year 2015-16, the year before scoring rubrics were introduced to conduct the evaluation process (Tiseira 2015). The analyzed courses are sequential in time. This allows to investigate whether training the soft skill during the first course has a noticeable effect on the second one. 


\section{Description of the courses}

\subsection{Aerospace Technology}

Aerospace Technology (AT) is a compulsory course offered to second-year students (about 120 students) of the Aerospace Engineering Bachelor Degree at UPV. It takes place during the first semester of the second year (fall semester) and covers 4.5 ECTS. This is the first course of the curriculum that specifically deals with aircraft. It is aimed at providing the students with a general view of Aerospace Engineering and the associated technologies implemented. Thus, it may be seen as a link among the basic disciplines (mathematics, physics, etc., studied during the 1st year of the degree) and the applied ones, specific of this degree. Its contents are divided in 2 parts: atmospheric flight aircraft (with 3 different units) and space vehicles (with 2 units).

In addition to working specific competences of the degree, the students train the UPV "Effective communication" soft skill. This skill is developed in both its written and oral aspects. Hence, the evaluation of this course (Delgado 2006) comprises two open-answer exams (30\% of the final grade), two multiple-choice tests (30\%), an academic assignment assessed through a written report $(30 \%)$ and the observation of laboratory sessions (which includes an oral presentation, $10 \%)$.

It is important to note that, as part of the training of the soft skill object of investigation, a session within Unit 2 of atmospheric flight aircraft part is specifically devoted to give guidelines to produce written reports, addressing their structure, how to include and reference figures and tables, which language register to use and how to properly cite external information. This session is designed with a practical point of view including recommendations and tips to communicate effectively together with issues to be avoided when writing. Particular examples are extracted from the reports handed by students of previous years.

\subsubsection{AT assignment}

The academic assignment for which a written report must be handed consists on analyzing a real aircraft on the view of the theoretical lectures. Each student or group of students need to pick a different aircraft. In short, they are asked to perform three different kinds of tasks:

- Research tasks to get to know the aircraft specifications (3-view drawings, weights breakdown, cruise speed, cruise altitude, powerplant...).

- Analysis tasks: reasoning the aircraft configuration and structure, justifying the arrangement of systems within the aircraft according to its mission. 
- Simple calculations concerning aerodynamics and performance, with basic tools that will improve in following courses. An analysis of the results is demanded.

Thus, besides applying concepts and providing descriptive work, it is intended that the students get familiar with some order of magnitude of the relevant parameters of real aircraft (weights, thrust, aerodynamic parameters, ...) through self-discovery.

The written report is evaluated through a scoring rubric (Tiseira 2015, Maldini 2010). Indicators of the rubric cover two different aspects: several dimensions merely related to its contents are assessed as 'Unsatisfactory' (0 to 4 marks), 'Fair' (5 to 7), 'Good' (8 to 9) or 'Excellent' (10) whose marks are additive; and language and appearance dimensions deemed to contribute to an effective communication, assessed from D to A. These grades are numerically assigned values from 0.7 to 1 and act as multiplicative factors to the previous ones in order to compute the final grades.

It is important to note that the assignment has suffered some modifications since the introduction of the rubric in the 2016-17 academic year, which are summarized as follows:

- To compensate for the growing complexity of the assignment, it is carried out in groups of 3 or 4 students from the introduction of the rubric in 2016-2017.

- In order to provide feedback to the students prior to the final submission, an intermediate submission was introduced in 2018-19. The impact of this action is analyzed in this work.

\subsection{Advanced Fluid Mechanics}

Advanced Fluid Dynamics (AFM) is an elective course offered to third-year students of the Degree, although students in its fourth year may also take it (80 to 100 students enroll each year). The course is held during the first semester of the academic year, covering 4.5 ECTS. It is the continuation of a compulsory Fluid Mechanics (FM) course, which is taught during the second year. Both courses are carefully coordinated regarding shared contents, in order to promote the acquisition of the "01 - Comprehension and integration" soft skill (Dolz 2017). The contents treated in AFM are also divided in two parts: the first one can be considered as a continuation or extension of a corresponding unit in FM, meanwhile the second introduce to the student a useful tool to solve all fluid dynamics problems, such as Computational Fluid Dynamics (CFD), and a new fluid dynamic problem, which is turbulence.

The evaluation of this course (Delgado 2006) comprises one written exam (30\% of the final grade), one multiple-choice test (30\%), observation of laboratory sessions (10\%) and one academic assignment (30\%), which is designed as a short CFD project. 


\subsubsection{AFM academic assignment}

AFM course project consists in solving any wall bounded flow problem the students may be interested in (open proposal) by means of CFD. By letting the students to come up with ideas for the topic of their project, they are involved in the project from the first step, which is setting the focus, refine the issue(s) and identify the stakeholder(s) (NOAA, 2009).

Together with the statement of the assignment, they are given guidelines to carry the project out successfully, and few examples organized by complexity. The evaluation rubric (Maldini, 2010) used to grade the report is also provided to the student in advance (Tiseria, 2015). It contains 5 criteria, 2 of them associated to the soft skill of study (formatting, writing), and the other 3 to technical or specific competences (difficulty of the study, procedure and results) to be evaluated in 4 different levels of performance, from A (highest) to D (lowest). This grading is later transformed to a numeric mark. Teachers also remind the students that they already have guidelines about how to write reports, and provide them again all the related material of AT.

\section{Effects on the technical contents of the reports}

A summary of the grades is presented in Tables 1 and 2 for the last four years and both courses. Results for the Advanced Fluid Mechanics course in the academic year 2015-2016 are not considered in this analysis because that generation of students did not carry out the written assignment the previous year in Aerospace Technology. The use of scoring rubrics allows differentiating the dimensions to be evaluated: Table 1 includes the results of the writing skills dimensions of the rubrics, whilst Table 2 considers the technical content of the reports. Results for the two first years of analysis of Aerospace Technology are not shown in Table 1 because the report was written and handed individually, not in groups, and that would not be comparable to the AFM assignment. The multiplicative factor of AT is converted to a scale of $0-10$, so results need to be carefully analyzed or they would be misleading. As far as the evaluation of the technical contents is concerned, the marks the students obtain in the Advanced Fluid Mechanics course are lower than the ones in Aerospace Technology in all cases. This could be associated to the difficulty of the course and the assignment itself, but also to a higher degree of freedom in the selection of the topic in that course. Even though they are warned by the professors in the beginning, some groups select a more difficult topic with the idea of obtaining a higher grade. 
Improving the effective communication soft skill in higher education engineering studies: an experience through written reports

Table 1. Evaluation results of writing skills (max. 10).

\begin{tabular}{|cccccc|}
\hline Year & Group & Average & Max. & Min. & Std. dev. \\
\hline $2015-2016$ & AT & - & - & - & - \\
$2015-2016$ & AFM & - & - & - & - \\
$2016-2017$ & AT & - & - & - & - \\
$2016-2017$ & AFM & 6.60 & 10 & 4.38 & 1.36 \\
$2017-2018$ & AT & 6.47 & 10 & 0 & 0.23 \\
$2017-2018$ & AFM & 5.31 & 8 & 3 & 1.27 \\
$2018-2019$ & AT & 6.50 & 10 & 0 & 0.27 \\
$2018-2019$ & AFM & 7.33 & 10 & 3.75 & 1.66 \\
\hline
\end{tabular}

From the collected data on the writing and formatting dimensions (Table 1), results vary from one year to another. Only the introduction of the intermediate delivery improves the average result obtained by the students. Even so, the minimum score does not significantly change, probably because this review system is not motivating all the individuals. This would also explain why the standard deviation is higher in the last evaluated academic year.

As it has been said, data on the writing skills are not provided for the Aerospace Technology course during 2015-2016 and 2016-2017. Nevertheless, it is the perception of the authors that the performance of the students in this regard is substantially improving. During the first years reported (2015-2016 and 2016-2017), some students did not include a bibliography section and did not cite external information, despite the warning that this constitutes plagiarism. After this resulting in failed assignments when applying the scoring rubric and after introducing the specific lecture about writing skills, properly referencing has now become a standard among students. Similarly, the formal and impersonal language of written reports is also progressively being adopted by them. Thus, the presented method of assessment forces the students to make an effort on communicating information effectively, hopefully adopting these practices for the rest of their academic studies as the increasing grades in this dimension for the AFM course could suggest. 
Table 2. Technical contents evaluation results (max. 10).

\begin{tabular}{|cccccc|}
\hline Year & Group & Average & Max. & Min. & Std. dev. \\
\hline $2015-2016$ & AT & 8.55 & 10.00 & 3.50 & 1.55 \\
$2015-2016$ & AFM & - & - & - & - \\
$2016-2017$ & AT & 8.15 & 10.00 & 2.20 & 2.12 \\
$2016-2017$ & AFM & 6.16 & 9.58 & 2.92 & 1.73 \\
$2017-2018$ & AT & 8.89 & 10.00 & 6.30 & 1.03 \\
$2017-2018$ & AFM & 6.72 & 10.00 & 3.75 & 1.37 \\
$2018-2019$ & AT & 9.33 & 10.00 & 7.20 & 0.77 \\
$2018-2019$ & AFM & 7.55 & 10.00 & 4.17 & 1.46 \\
\hline
\end{tabular}

Trends observed in the evaluation of the writing itself (Table 1) are not reproduced in the technical part (Table 2). The average grade is similar in the different academic years, and there is always at least one group of students that outstands in this aspect of the reports, but some improvements in the minimum value are observed, as well as a reduction in the standard deviation of the results (less significant in the Advanced Fluid Mechanics course). In the case of Aerospace Technology, there is a reduction in the minimum value and an increase in the standard deviation of the marks showing up during 2016-2017, when the rubric was introduced. After that year, important rises in the minimum grade and reductions in the standard deviation have been observed. Further improvements have been observed during 2018-2019, after introducing intermediate deliveries. This action has also a significant effect in the course of Advanced Fluid Mechanics, the average grade of the technical part of the report increases 0.80 points from one year to the next, increasing 0.40 the minimum value. However, a stronger impact is observed in the dimensions related to the written skills, with an increase of about 2.00 points.

\section{Perception of the students}

During 2018-2019 academic year, the students of Aerospace Technology took part on a survey about their experience and their results. Two of the questions were about the partial submission and about their performance. The overall opinion was positive towards performing partial submissions, and the students reported that they acquired new skills but 
they worked more than they should have. In addition, the subjective feeling of the authors of this work is that students feel somewhat saturated by the amount of work done. Complaints about overwork are not, however, due to the extra care that they have to communicate properly, but due to the level of demand of the technical content.

\section{Conclusions}

In this work, the experience of developing and assessing the effective written communication in the frame of two Aerospace Engineering courses is reported. Through progressive improvements made on the courses along the years, such as the introduction of a specific session devoted to this skill, the use of scoring rubrics or the splitting of the submission in different deliveries, an enhancement has been obtained in the readability of the reports delivered by the students. Forcing students to develop these skills during a 2nd year course seems to be translated into an improvement of the reports the same students produce in successive years. Even though no significant differences are noticed in the depth of the technical content they develop, they transmit more effectively these contents. With all, designing activities related to writing skills and a coherent evaluation procedure seems to allow students to produce reports that meet the standards in terms of use of language, format, citing and referencing.

\section{Acknowledgements}

This work has been done in the framework of the innovative teaching group EICE CONMAGIA promoted by the Instituto de Ciencias de la Educación of the Universitat Politècnica de València.

\section{References}

The Boeing Company (1996). Desired Attributes of an Engineer. Retrieved May 20 from http://people.cs.ksu.edu/ hankley/d501/Info/EngrAttributes.html.

The Bologna Declaration of 19 June 1999 (1999). The European Higher Education Area. Retrieved May 20 from https://www.eurashe.eu/library/bologna_1999_bologna-declaration-pdf/.

Crooks, T. J. (1988). Assessing Student Performance. Kensington, N.S.W.: Higher Education Research and Development Society of Australasia. 
Universitat Politècnica de València (2015). Proyecto Competencias Transversales UPV. Institutional communication, Valencia, Spain.

Koehler, T. P. (2001). Practical guide to effective written communication. Project Management Institute Annual Seminars \& Symposium, Nashville, USA. Newtown Square, PA: Project Management Institute.

Yusof, Y., Roddin, R. and Awang, H. (2015). What Students Need, and What Teacher Did: the Imact of Teacher's Teaching Approaches to the Development of Students' Generic Competences. Procedia - Social and Behavioral Sciences, 204, 36-44.

Masoud, M. I. and Al Muhaseb, A. H. (2019). Improving engineering student's writing/presentation skills using laboratory/mini-project report. International Journal of Electrical Engineering, Article In Press. DOI: 10.1177/0020720919833051.

Tiseira, A. O, Martí-Aldaraví, P., Navarro, R., Carreres, M. (2015). Use of scoring rubrics for evaluating oral presentations in aerospace engineering education. In: Proceedings of the $1 \mathrm{st}$ International Conference on Higher Education Advances (Head'15, Valencia), 50-56.

Delgado, A. M. and Oliver, R. (2006). La evaluación en un nuevo escenario docente. Revista de Universidad Sociedad del Conocimiento, 3, 1-13.

Dolz, V., Pla, B., Navarro, R. and Martí-Aldaraví, P. (2017). On the adequacy of courses sharing contents. In: International Conference on Innovation, Documentation and Education (INNODOCT 2017), October, 25th-27th, Valencia, Spain

Maldini, Y. and Andrade, H. (2010). A review of rubric use in higher education. Assessment and Evaluation in Higher Education, 35(4), 435-448. DOI: 10.1080/02602930902862859. 